\title{
A Hemicyanine-Conjugated Copolymer as a Highly Sensitive Fluorescent Thermometer
}

Yasuhiro Shiraishi,* Ryo Miyamoto, and Takayuki Hirai

Research Center for Solar Energy Chemistry, and Division of Chemical Engineering, Graduate School of Engineering Science, Osaka University, Toyonaka 560-8531, Japan

E-mail: shiraish@cheng.es.osaka-u.ac.jp

\section{Supporting Information}

\section{Contents}

page

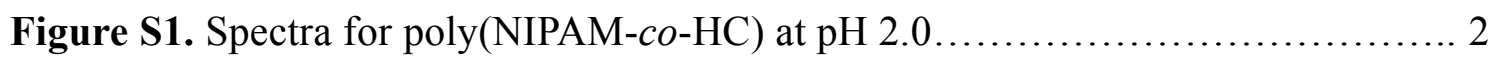

Figure S2. Spectra for 1 measured with HC-free polyNIPAM.......................... 3

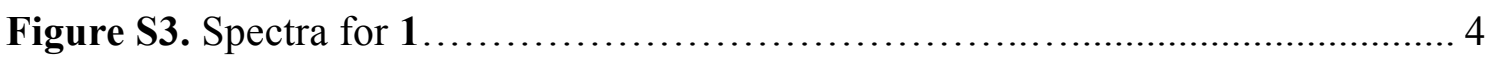

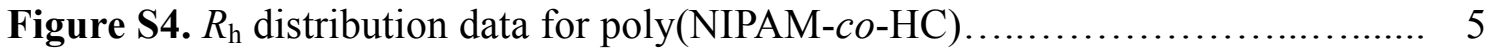

Figure S5. Spectra of 1 measured in respective solvents.......................... 5

Figure S6. Change in turbidity and $R_{\mathrm{h}}$ of HC-free polyNIPAM................................ 6

Figure S7. Change in absorption spectra of poly(NIPAM-co-HC) ................. 6

Figure S8. ${ }^{1} \mathrm{H}$ NMR spectrum of $\mathbf{1}$ in DMSO .................................... 7

Figure S9. ${ }^{13} \mathrm{C}$ NMR spectrum of $\mathbf{1}$ in DMSO.............................. 8

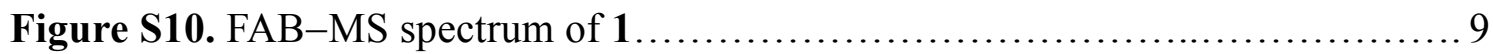

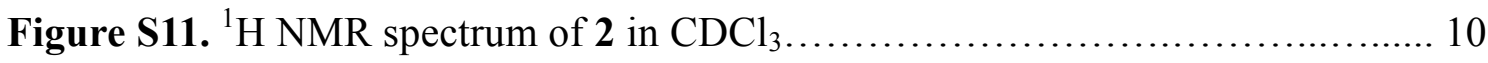

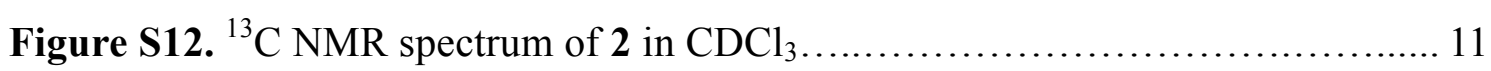

Figure S13. FAB-MS spectrum of 2 .................................... 12 

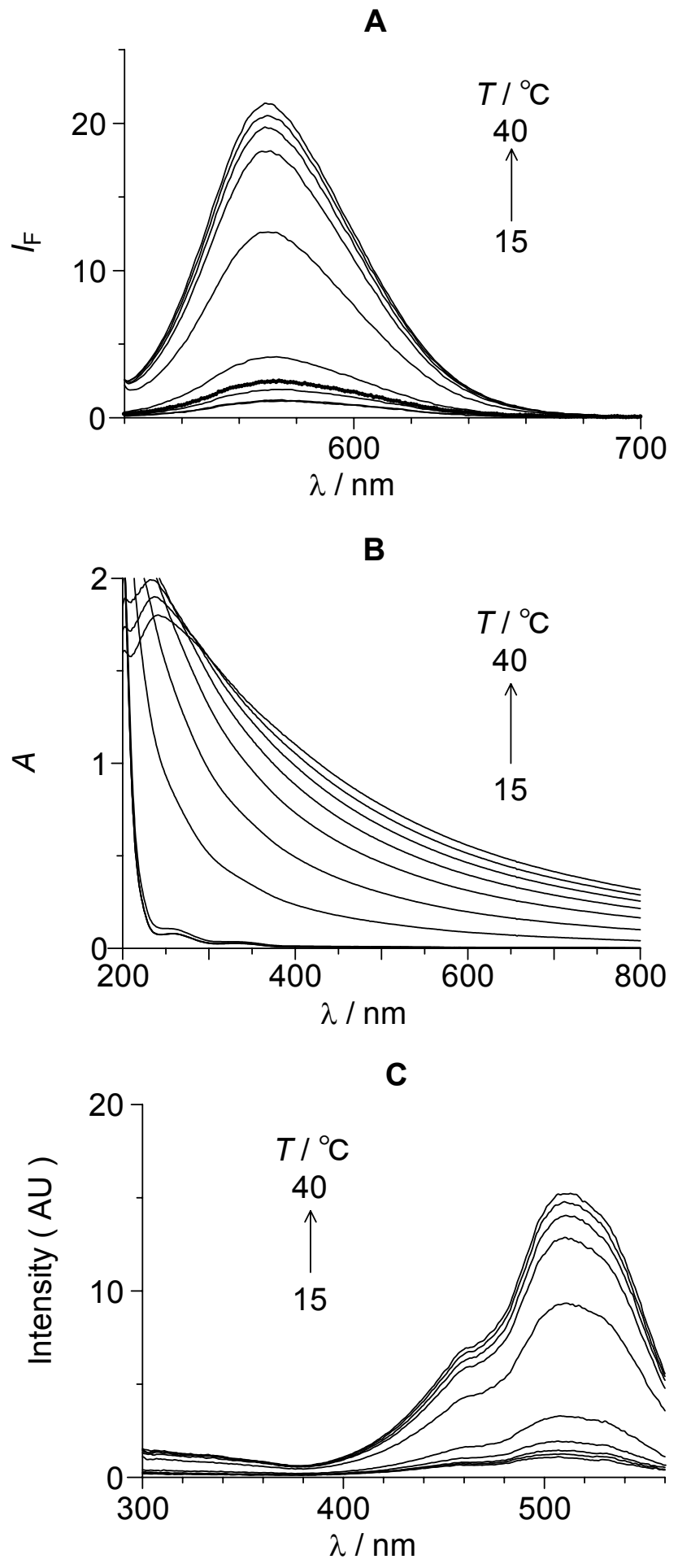

Figure S1. Temperature-dependent change in (A) fluorescence $\left(\lambda_{\mathrm{exc}}=510 \mathrm{~nm}\right)$, (B) absorption, and $(\mathrm{C})$ excitation spectra $\left(\lambda_{\mathrm{em}}=580 \mathrm{~nm}\right)$ of poly(NIPAM-co-HC) $\left(0.1 \mathrm{~g} \mathrm{~L}^{-1}\right)$ measured in water $(\mathrm{pH} 2.0)$. The measurements were done during heating sequence. 

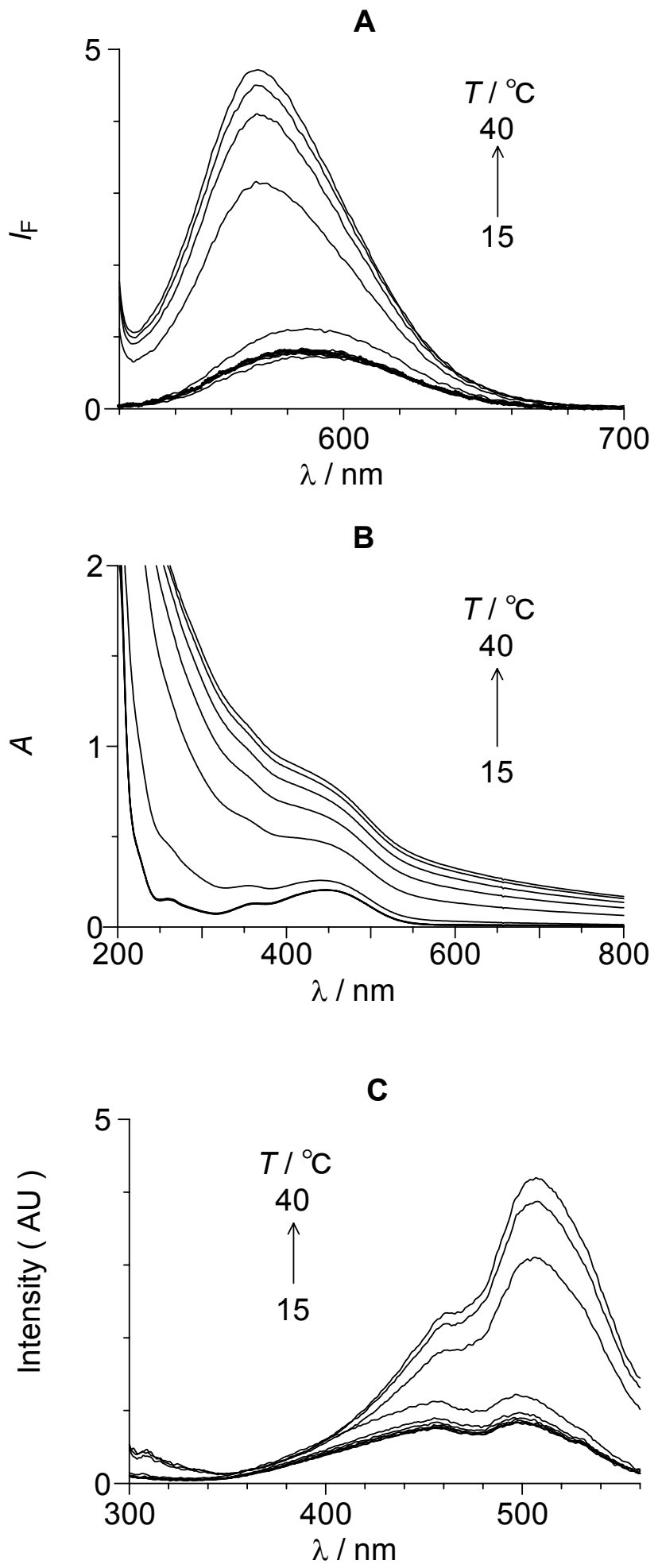

Figure S2. Temperature-dependent change in (A) fluorescence $\left(\lambda_{\text {exc }}=510 \mathrm{~nm}\right)$, (B) absorption, and $(C)$ excitation spectra $\left(\lambda_{\mathrm{em}}=580 \mathrm{~nm}\right)$ of $\mathbf{1}(13.7 \mu \mathrm{M})$ measured in water $(\mathrm{pH}$ 6.3) together with HC-free polyNIPAM $\left(0.1 \mathrm{~g} \mathrm{~L}^{-1}\right)$. The measurements were done during heating sequence. 

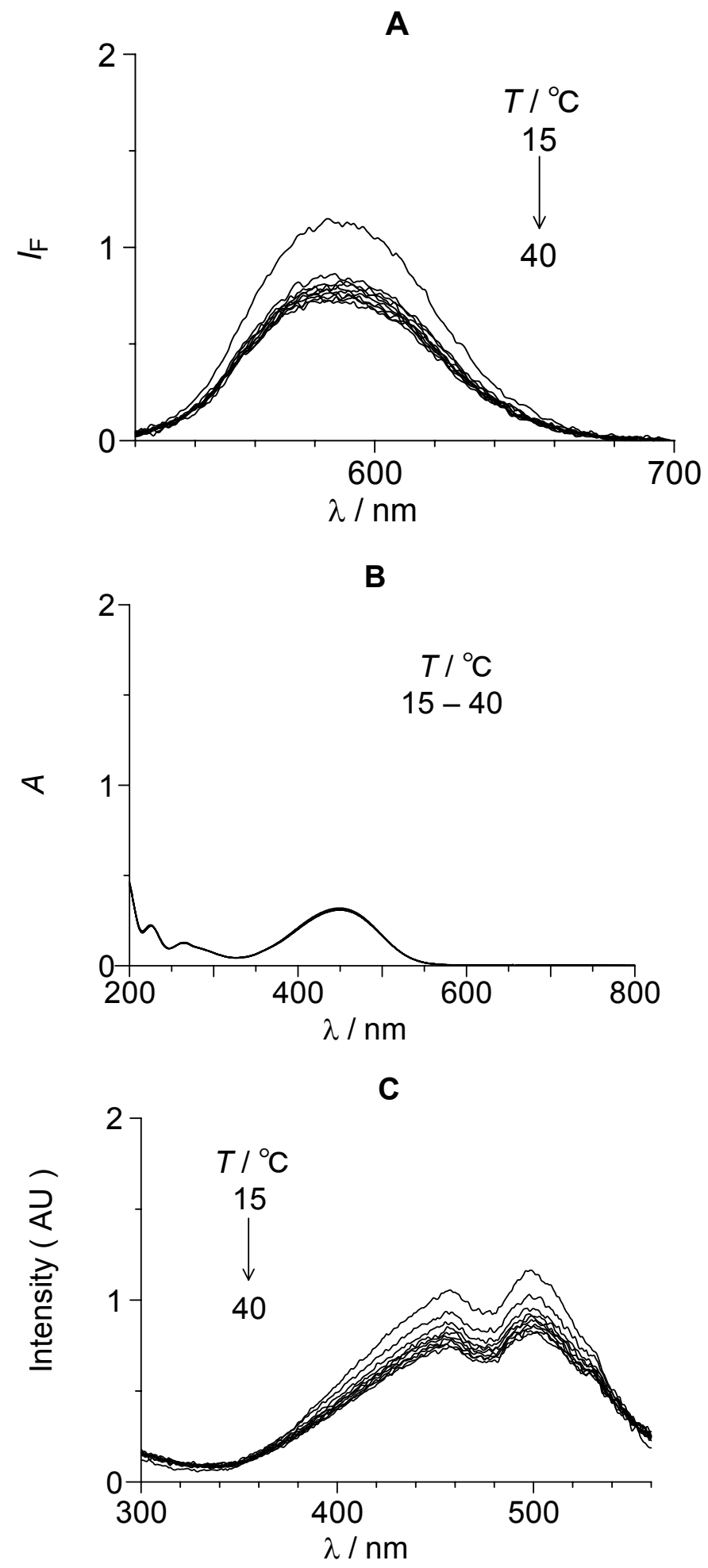

Figure S3. Temperature-dependent change in (A) fluorescence $\left(\lambda_{\text {exc }}=510 \mathrm{~nm}\right)$, (B) absorption, and $(C)$ excitation spectra $\left(\lambda_{\mathrm{em}}=580 \mathrm{~nm}\right)$ of $\mathbf{1}(13.7 \mu \mathrm{M})$ measured in water $(\mathrm{pH}$ $6.3)$. The measurements were done during heating sequence. 


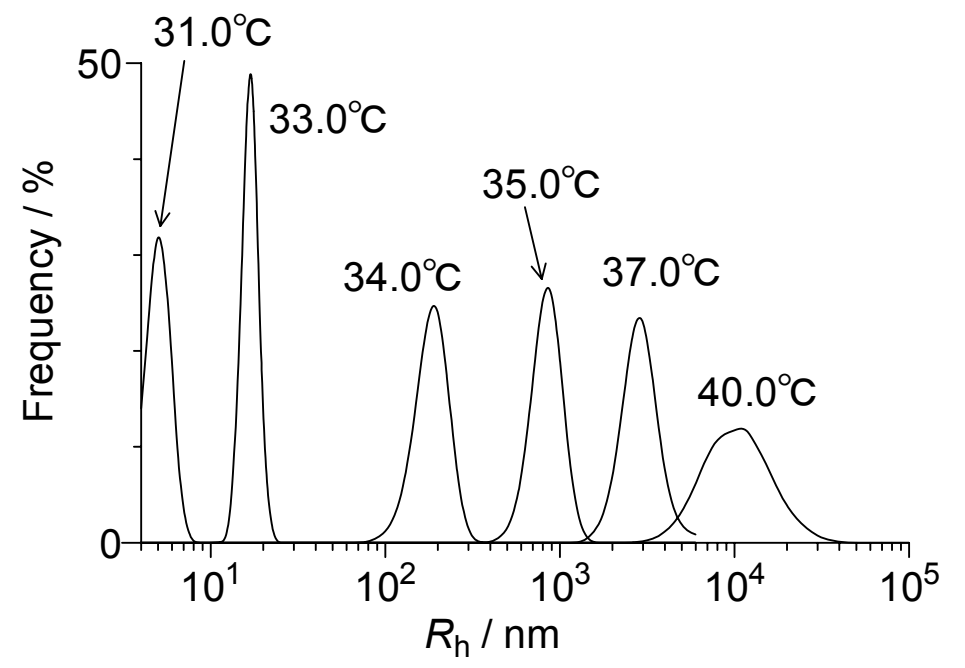

Figure S4. Temperature-dependent change in distribution of hydrodynamic radius $\left(R_{\mathrm{h}}\right)$ of poly(NIPAM-co-RD) $\left(0.1 \mathrm{~g} \mathrm{~L}^{-1}\right)$ dissolved in water $(\mathrm{pH} 6.4)$. The measurements were done during heating sequence.
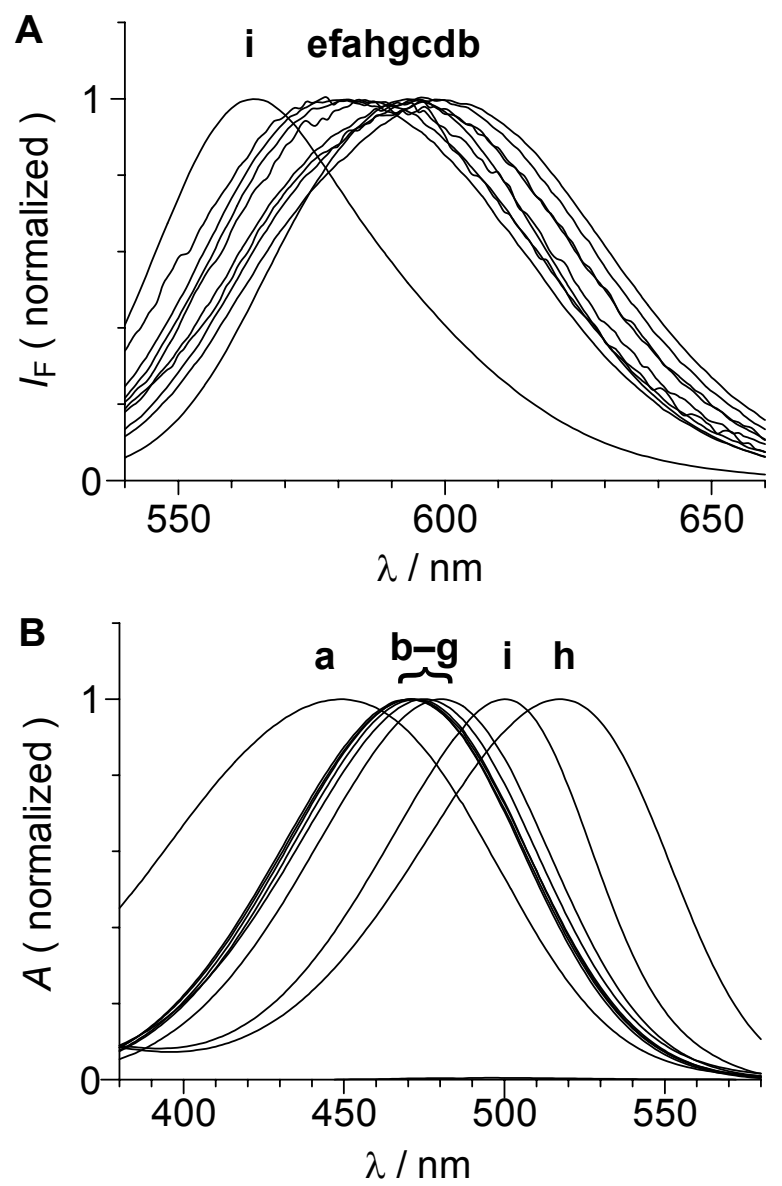

Figure S5. (A) Normalized fluorescence spectra $\left(\lambda_{\mathrm{exc}}=510 \mathrm{~nm}\right)$ and (B) normalized absorption spectra of $\mathbf{1}$ measured in respective solvents $(\mathrm{a}-\mathrm{i})$ at $25{ }^{\circ} \mathrm{C}$. The respective solvents correspond to that in Table 1. 


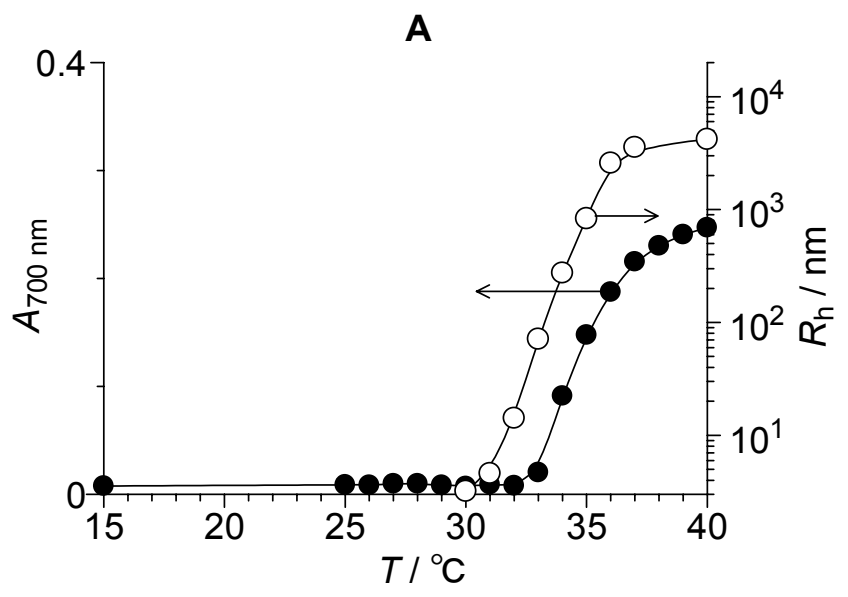

B

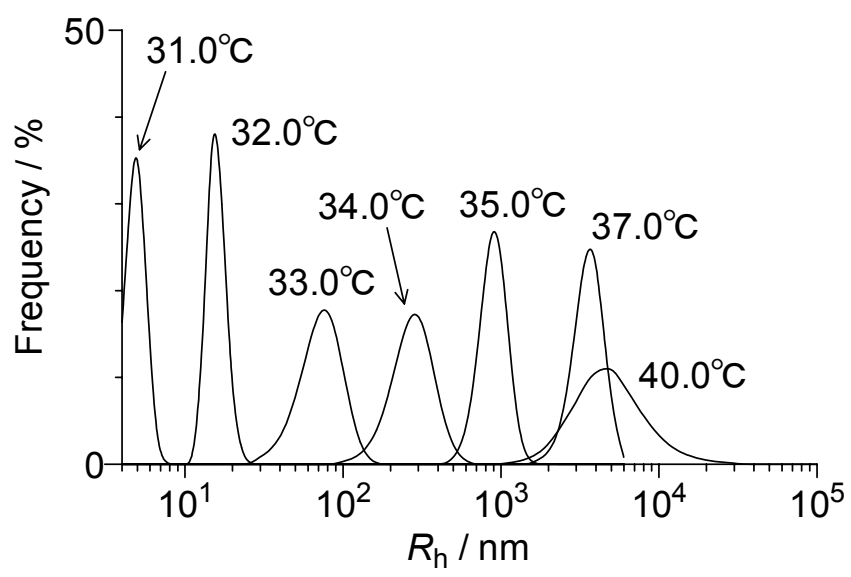

Figure S6. Temperature-dependent change in (A) (black) turbidity $\left(A_{700 \mathrm{~nm}}\right)$ and (white) hydrodynamic radius $\left(R_{\mathrm{h}}\right)$ of polyNIPAM $\left(0.1 \mathrm{~g} \mathrm{~L}^{-1}\right)$ dissolved in aqueous solution $(\mathrm{pH} 6.3)$. (B) The detailed $R_{\mathrm{h}}$ distribution data. The measurements were done during heating sequence.

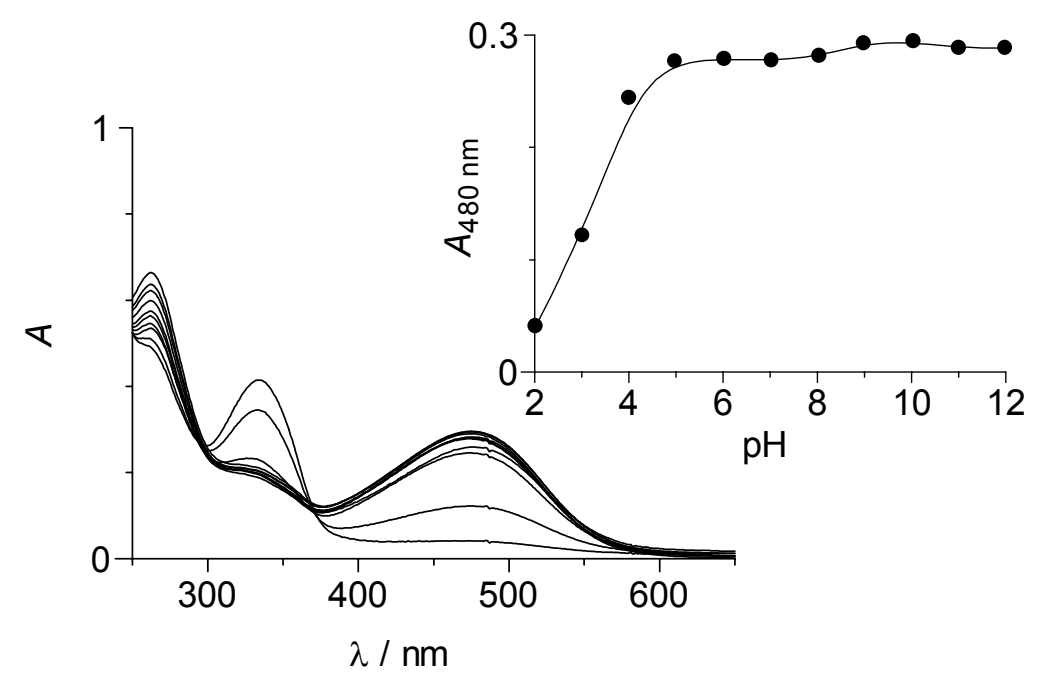

Figure S7. $\mathrm{pH}$-dependent change in absorption spectra of aqueous solution containing poly(NIPAM-co-HC) $\left(0.1 \mathrm{~g} \mathrm{~L}^{-1}\right)$ measured at $20^{\circ} \mathrm{C}$. 


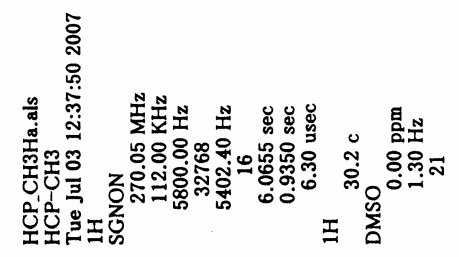

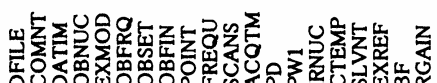

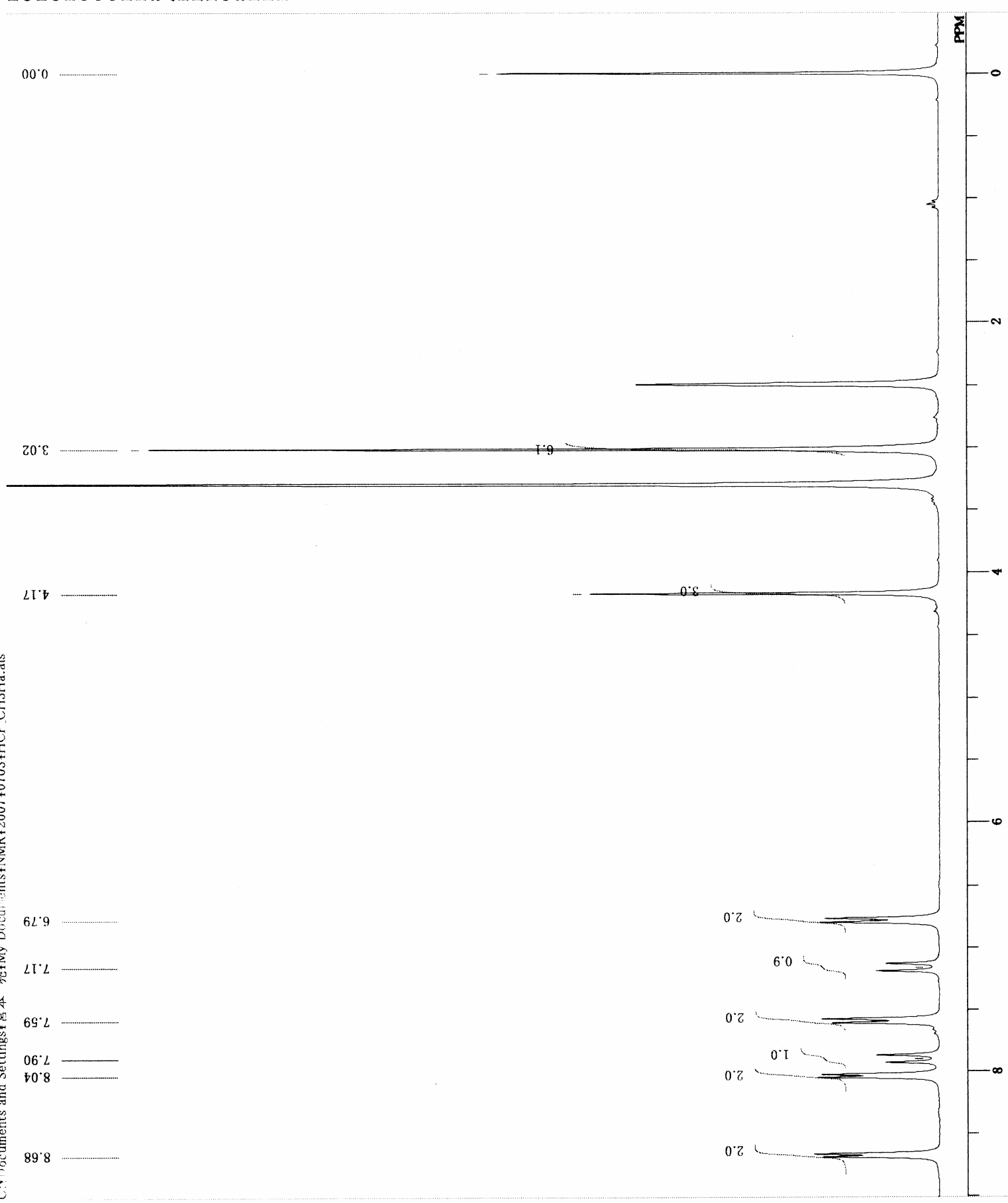

Figure S8. ${ }^{1} \mathrm{H}$ NMR spectrum of $\mathbf{1}$ in DMSO. 


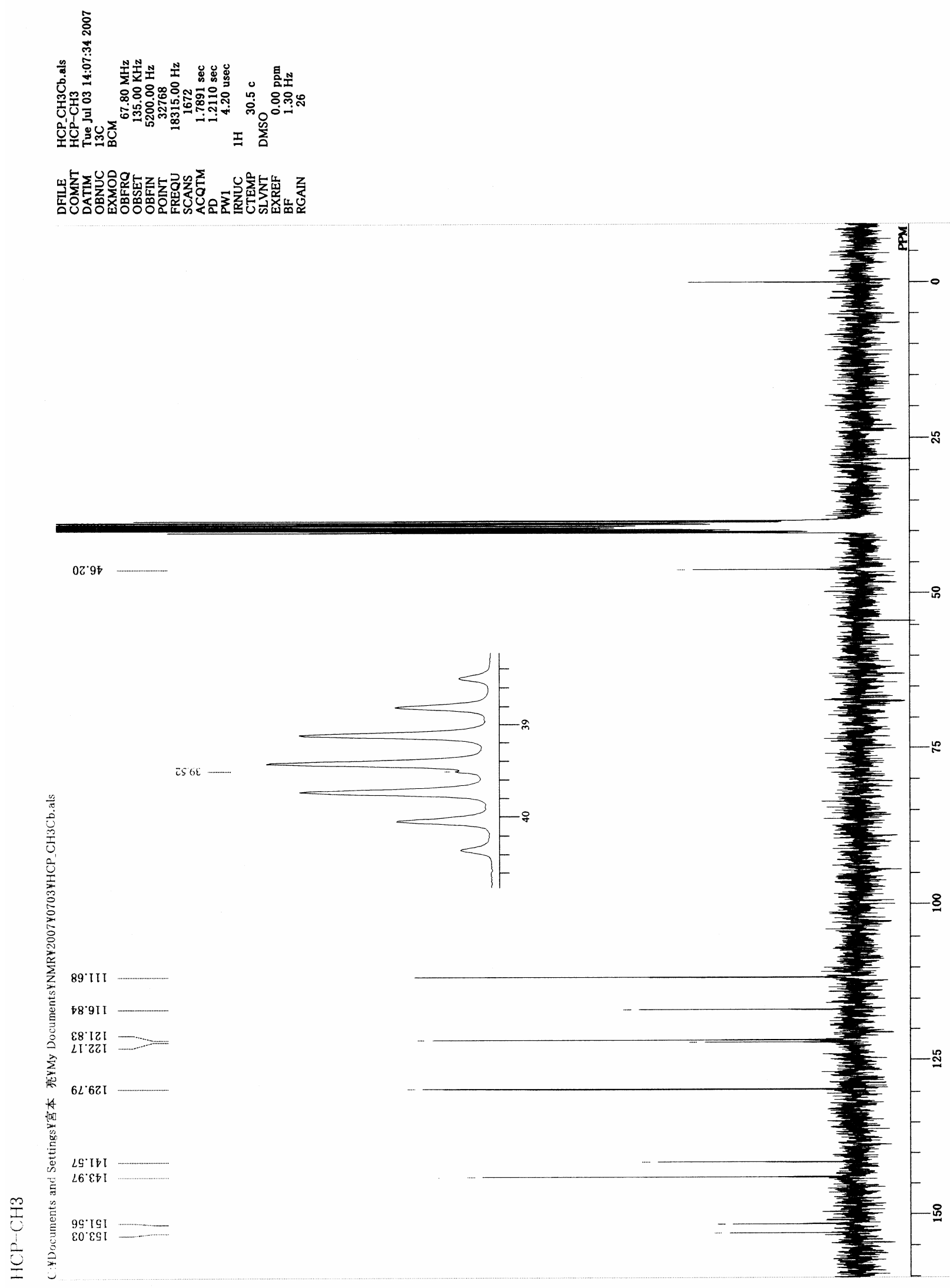

Figure S9. ${ }^{13} \mathrm{C}$ NMR spectrum of $\mathbf{1}$ in DMSO. 


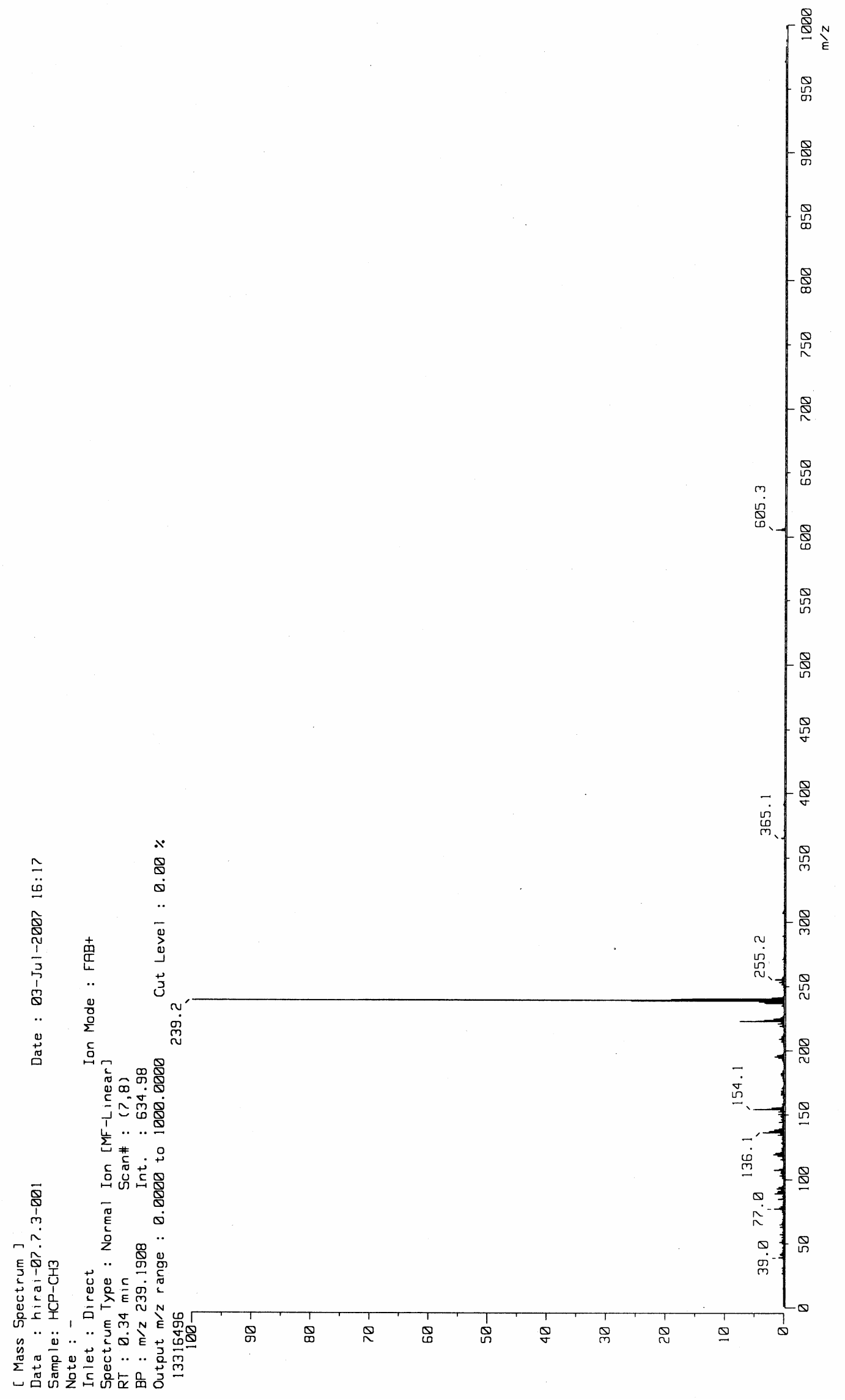

Figure S10. FAB-MS spectrum of 1. 


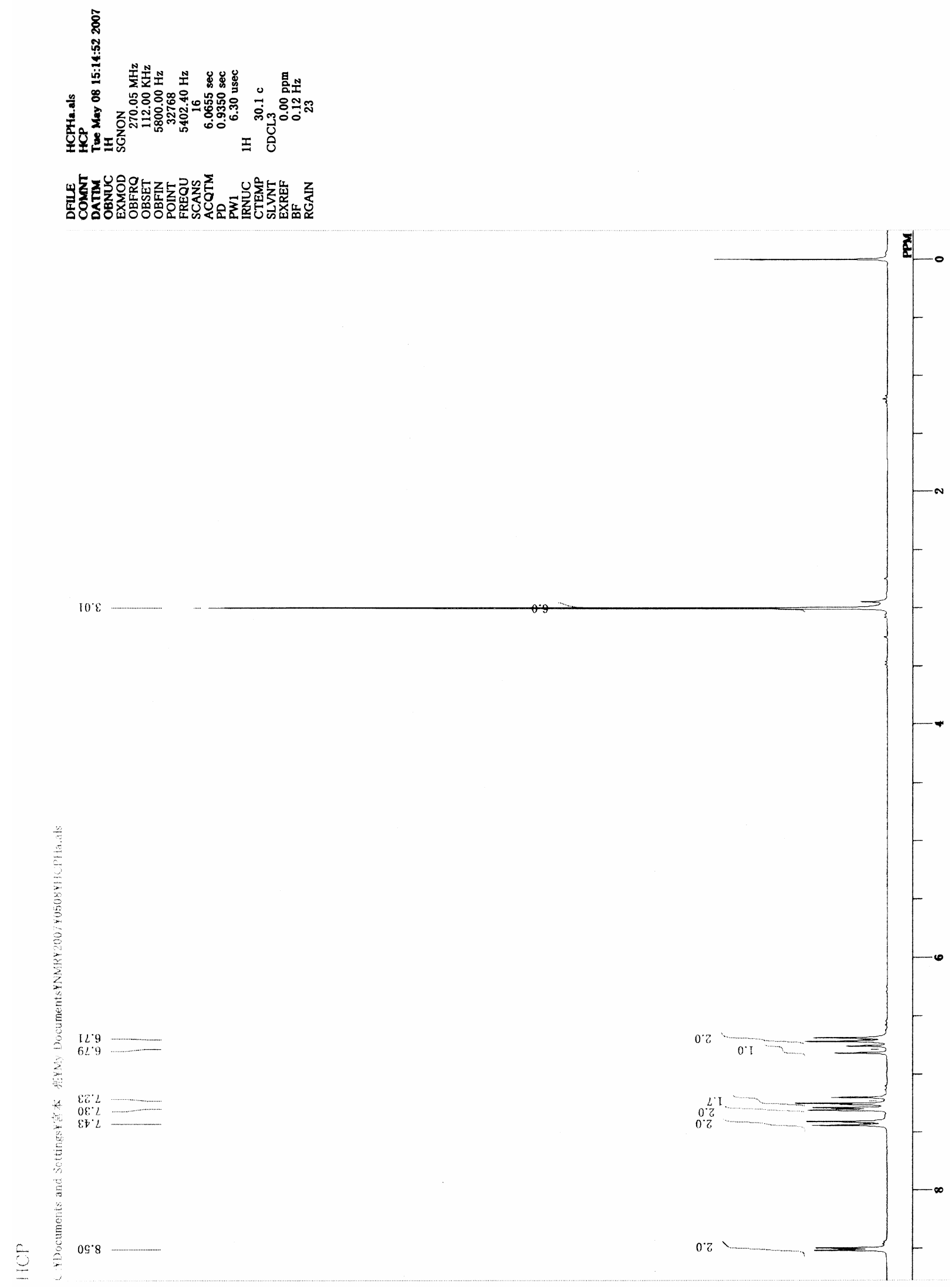

Figure S11. ${ }^{1} \mathrm{H}$ NMR spectrum of 2 in $\mathrm{CDCl}_{3}$ 


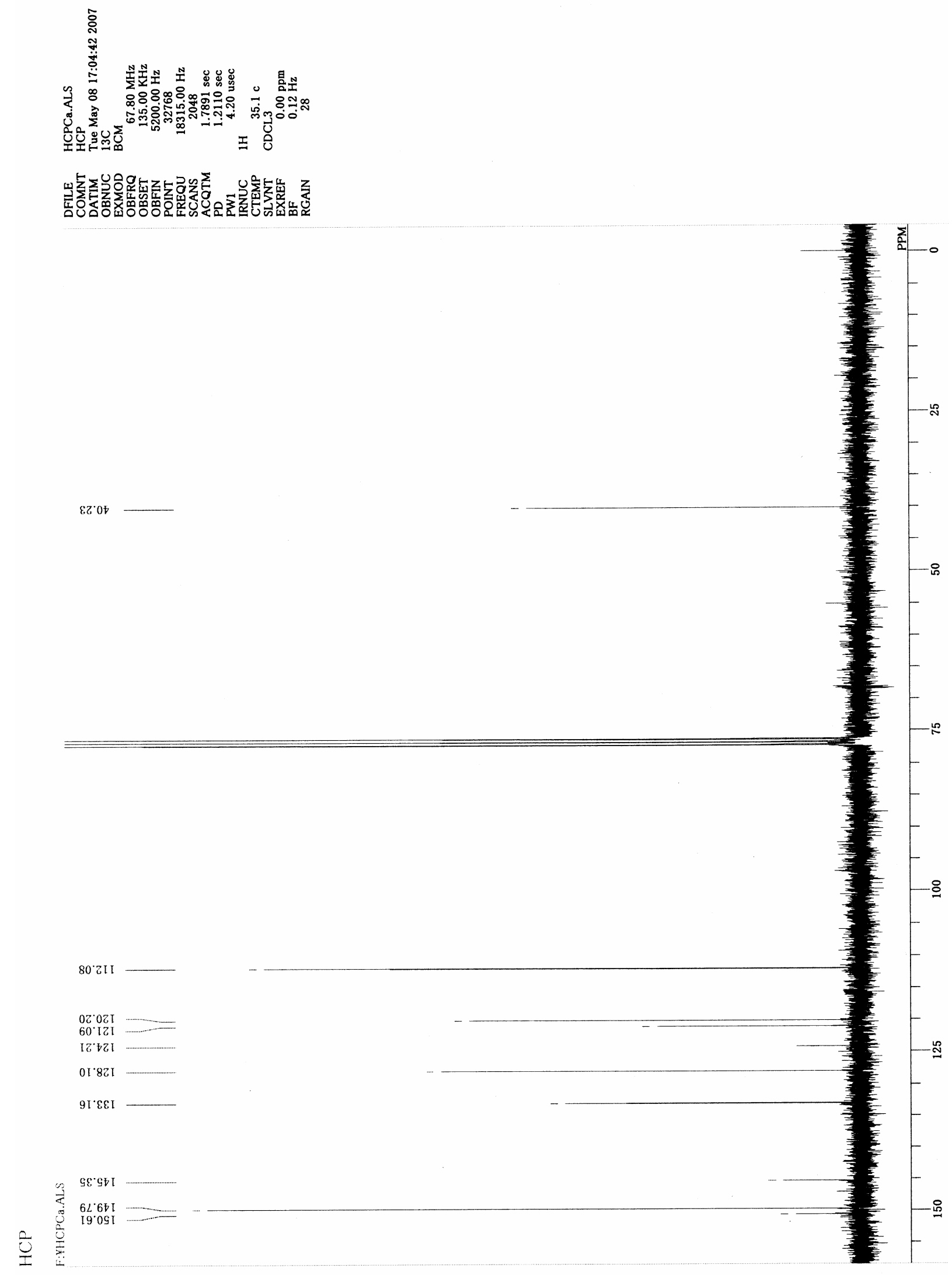

Figure S12. ${ }^{13} \mathrm{C}$ NMR spectrum of 2 in $\mathrm{CDCl}_{3}$ 


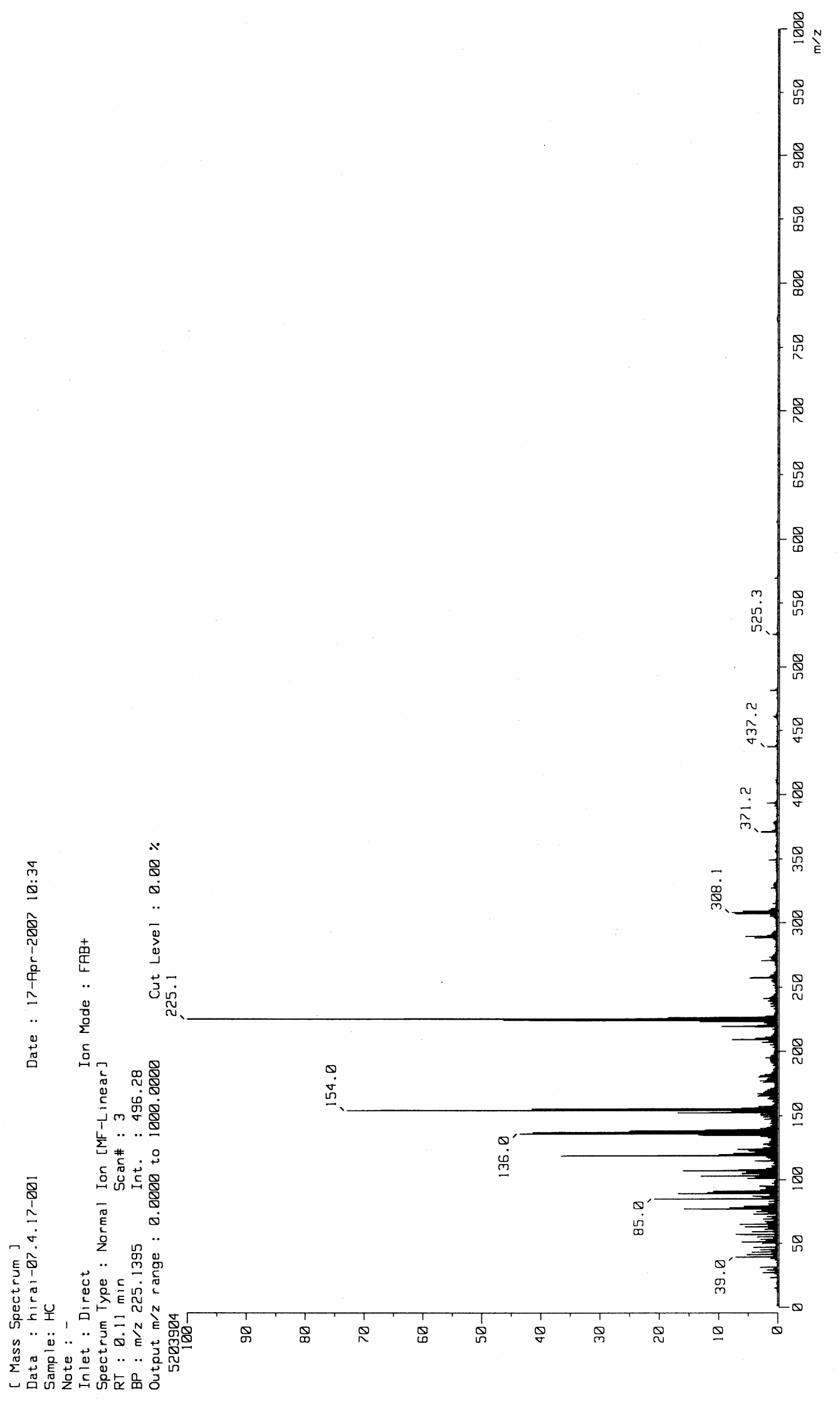

Figure S13. FAB-MS spectrum of 2. 